\title{
Catalyst Optimization from Structural and Chemical Analysis of Individual Au-Pd Nanoparticles Using Aberration Corrected STEM
}

${\text { Qian } \mathrm{He}^{1 *}}^{*}$, Meenakshisundaram Sankar ${ }^{2 * *}$, James Pritchard ${ }^{2}$, Moataz Morad $^{2}$, Simon J. Freakley ${ }^{2}$, Jennifer K. Edwards ${ }^{2}$, Stuart H. Taylor ${ }^{2}$, Albert F. Carley ${ }^{2}$, Graham J. Hutchings ${ }^{2}$, Christopher J. Kiely ${ }^{1}$

1. Department of Materials Science and Engineering, Lehigh University, PA 18015 U.S.A.

2. Cardiff Catalysis Institute, School of Chemistry, Cardiff University, Wales, U.K.

* Currently at Oak Ridge National Lab, TN, U.S.A ** Currently at Utrecht University, The Netherlands.

Structural and chemical information acquired from individual bimetallic nanoparticles are indispensable for understanding and optimizing their catalytic properties. In this work, Au$\mathrm{Pd} / \mathrm{TiO}_{2}$ catalysts prepared by different methods are compared by HAADF imaging and XEDS analysis in an aberration corrected JEOL 2200FS STEM. Developing preparation-structureperformance correlations in this way has allowed us to devise a novel catalyst preparation method for $\mathrm{Au}-\mathrm{Pd} / \mathrm{TiO}_{2}$ catalysts, which display a 3-fold improvement in catalytic performance, without changing the metal content or precursor, for the direct synthesis of hydrogen peroxide from molecular hydrogen and oxygen.

We first studied two commonly used synthesis methods for preparing $\mathrm{Au}-\mathrm{Pd} / \mathrm{TiO} \mathrm{O}_{2}$ catalysts, namely conventional wet-impregnation $\left(\mathrm{C}_{\mathrm{Im}}\right)$ and sol-immobilization $\left(\mathrm{S}_{\mathrm{Im}}\right)$. The $\mathrm{C}_{\mathrm{Im}}$ method involves adsorption of aqueous solutions of $\mathrm{HAuCl}_{4}$ and $\mathrm{PdCl}_{2}$ salts onto the $\mathrm{TiO}_{2}$ support, followed by drying and a calcination treatment in air. This results in the formation $\sim 10 \mathrm{~nm} \mathrm{Pd-}$ rich shell/Au-rich core particles, along with um scale Au-rich particles and sub-nm Pd-rich clusters. Despite the limited control over particle size and composition, the $\mathrm{C}_{\mathrm{Im}}$ method has the important merit of simplicity. In the case of the $\mathrm{S}_{\mathrm{Im}}$ method, Au-Pd nanoparticles were preformed in the aqueous phase by simultaneously reducing $\mathrm{HAuCl}_{4}$ and $\mathrm{PdCl}_{2}$ in the presence of a stabilizer ligand PVA, and subsequently immobilized onto the $\mathrm{TiO}_{2}$ support. This results on the formation of 1-6 nm homogeneous Au-Pd alloy particles, which display a superior catalytic performance to the $\mathrm{C}_{\mathrm{Im}}$ materials. However a systematic size-dependent composition variation was also identified in $\mathrm{S}_{\mathrm{Im}}$ materials, indicating that the composition control by $\mathrm{S}_{\mathrm{Im}}$ is limited. Furthermore, the $\mathrm{S}_{\mathrm{Im}}$ method is not easy to scale-up for mass production.

Our goal was to develop a new synthesis method that is as simple as $\mathrm{C}_{\mathrm{Im}}$, yet provides even better size and composition control than $\mathrm{S}_{\mathrm{Im}}$. We achieved this by first adding an excess amount of $\mathrm{Cl}^{-}$, in the form of $\mathrm{HCl}$, into the precursor solution used in the original $\mathrm{C}_{\mathrm{Im}}$ route, and then replacing the air calcination treatment with a heat treatment in a reducing $5 \% \mathrm{H}_{2} / \mathrm{Ar}$ atmosphere. There are several benefits of using this so-called modified impregnation method $\left(\mathrm{M}_{\mathrm{Im}}\right)$. Firstly, the heat treatment in a reducing atmosphere shrinks the mean particle size and also eliminates core-shell morphology structures. As shown in Figure 1, the $\mathrm{M}_{\mathrm{Im}}$ catalyst subjected to a reducing atmosphere has a 1-6 nm particle size and a homogeneous alloy structure (Figs. 1 (a) \& (b)), In comparison, the $\mathrm{M}_{\mathrm{Im}}$ material calcined in air generates particles which are $\sim 10 \mathrm{~nm}$ in size and have distinctive Pd-rich shell/Au-rich core structures (Figs. 1 (c) \& (d)). Secondly, the effect of the excess $\mathrm{Cl}^{-}$was to direct $\mathrm{Au}$ into the bimetallic nanoparticles, instead of the um-scale 
particles. As shown in Figure 2, the average Pd concentration in the nanoparticles progressively drops from $75 \mathrm{wt} \%$ to $51 \mathrm{wt} \%$ to $30 \mathrm{wt} \%$ if using $0 \mathrm{M}$ (black triangles), $0.58 \mathrm{M}$ (red squares) or $2 \mathrm{M}$ (blue circles) excess $\mathrm{HCl}$ respectively. It is remarkable that using this simple $\mathrm{M}_{\mathrm{Im}}$ technique, the size, structure and composition of the Au-Pd alloy particles could all be successfully controlled to a much higher degree of precision than the $\mathrm{C}_{\operatorname{Im}}$ or $\mathrm{S}_{\operatorname{Im}}$ methods. The optimum productivity of hydrogen peroxide for the $\mathrm{M}_{\mathrm{Im}}$ material reached $99 \mathrm{~mol} \mathrm{H}_{2} \mathrm{O}_{2} \mathrm{~kg}_{\mathrm{cat}}{ }^{-1} \mathrm{~h}^{-1}$, which is at least a factor of three better than materials prepared by the more conventional methods $\left(32\right.$ mol H$_{2} \mathrm{O}_{2} \mathrm{~kg}_{\text {cat }}{ }^{-1} \mathrm{~h}^{-1}$ for $\mathrm{S}_{\mathrm{Im}}$ material and $23 \mathrm{~mol} \mathrm{H}_{2} \mathrm{O}_{2} \mathrm{~kg}_{\mathrm{cat}}{ }^{-1} \mathrm{~h}^{-1}$ for $\mathrm{C}_{\mathrm{Im}}$ material).
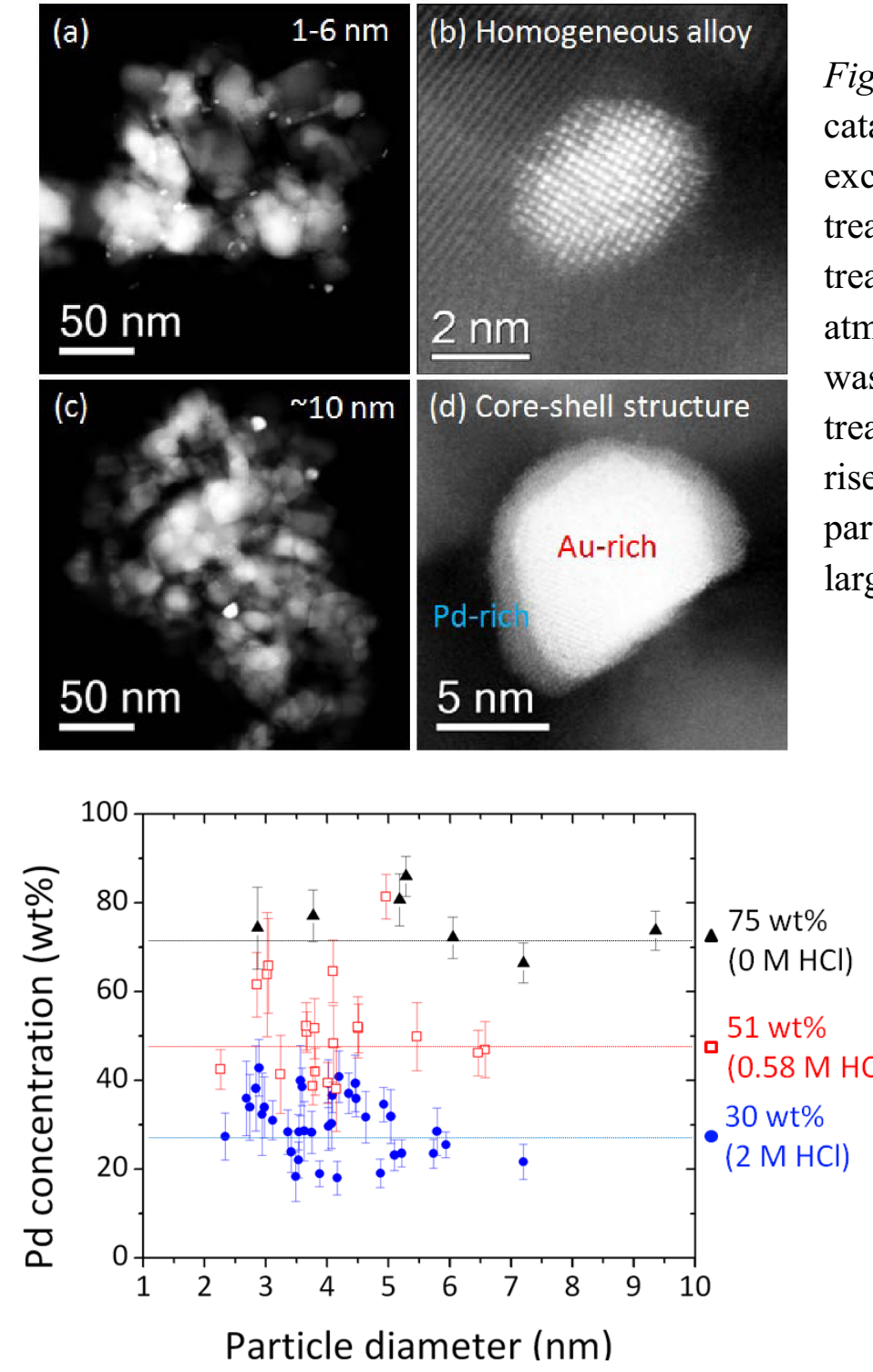

Figure 1 HAADF images of $\mathrm{Au}-\mathrm{Pd} / \mathrm{TiO}_{2}$ catalysts prepared by $\mathrm{M}_{\mathrm{Im}}$ with $0.58 \mathrm{M}$ excess $\mathrm{HCl}$, but subjected to different heat treatments. The sample in $(\mathrm{a}, \mathrm{b})$ was heat treated at $400^{\circ} \mathrm{C}$ in a reducing $\left(5 \% \mathrm{H}_{2} / \mathrm{Ar}\right)$ atmosphere, whereas that shown in $(\mathrm{c}, \mathrm{d})$ was calcined at $400^{\circ} \mathrm{C}$ in air. It is clear that treatment in a reducing atmosphere gives rise to smaller homogeneous alloy particles, whereas calcination in air creates larger Au-rich core-Pd rich shell particles.

Figure 2 Individual particle compositions plotted against particle diameter for $\mathrm{Au}-\mathrm{Pd} / \mathrm{TiO}_{2}$ catalysts prepared by $\mathrm{M}_{\mathrm{Im}}$ with $0 \mathrm{M}$ (black triangles), $0.58 \mathrm{M}$ (red squares) and $2 \mathrm{M}$ excess $\mathrm{HCl}$ (blue circles) added. The average $\mathrm{Pd}$ concentration drops from $75 \mathrm{wt} \%$ to $30 \mathrm{wt} \%$ with the increase in amount of excess $\mathrm{HCl}$ used, indicating that $\mathrm{Au}$ is being more efficiently incorporated into the nanoparticles.

Reference: 1. Sankar, M., He, Q., Kiely CJ., Hutchings GJ. et al. ACS Nano, 2012, 6, 6600-6613. 